\title{
Eye Care by Dutch Nursing Home Physicians: A Descriptive Study
}

\author{
Marianne M. Sinoo (Corresponding author) \\ Research Centre for Innovations in Health Care, Research Group Demand Driven Care \\ Utrecht
}

Heidelberglaan 7, 3584 CS Utrecht, the Netherlands

E-mail: marianne.sinoo@hu.nl Tel: +31 (0) 884815119

\begin{abstract}
Jos M. G. A. Schols
Caphri-School for Public Health and Primary Care, Maastricht University, Department of Family Medicine and Department of Health Services Research

PO Box 616, 6200 MD Maastricht, the Netherlands.

E-mail: jos.schols@maastrichtuniversity.nl Tel: +31 655866636
\end{abstract}

\begin{abstract}
Mirjam M. A. van Tilborg
Research Centre for Innovations in Health Care, Research Group Demand Driven Care Utrecht

Heidelberglaan 7, 3584 CS Utrecht, the Netherlands

E-mail: mirjam.vantilborg@hu.nl Tel: +31 (0) 884815342
\end{abstract}

Helianthe S. M. Kort

Research Centre for Innovations in Health Care, Research Group Demand Driven Care Utrecht

${ }^{1}$ Heidelberglaan 7, 3584 CS Utrecht, the Netherlands

E-mail: helianthe.kort@hu.nl Tel: +31 (0) 884815342

${ }^{2}$ Eindhoven University of Technology, Department of the Built Environment

Postbus 513, $5600 \mathrm{MB}$, Eindhoven, the Netherlands

E-mail: h.s.m.kort@tue.nl 
Received: October 29, 2015 Accepted: December 5, 2015 Published: December 8, 2015

doi:10.5296/jsss.v3i1.8502

URL: http://dx.doi.org/10.5296/jsss.v3i1.8502

\begin{abstract}
Currently, $4 \%$ of older adults reside in long-term care facilities in the Netherlands. Nursing home residents tend to have multimorbidity that is associated with considerable disabilities and a high level of care dependency. In the Dutch adult population the highest estimated prevalence $(>40 \%)$ of visual impairment (low vision and blindness) was found in the subgroup of residents in nursing homes (NHs). The aim of this study is to describe the current practice of eye care by Dutch nursing home physicians (NHPs).

A digital online survey was developed to describe the eye care activities of nursing home physicians and their cooperation in this perspective with other professionals.

Of 1573 NHPs present in the Netherlands, 125 (8\%) responded.

Results show that more than $50 \%$ of the NHPs regularly examine 'distant vision', 'near vision' and 'the visual field'. However, $23 \%, 33 \%$ and $45 \%$ almost never or never examine the 'visual field', 'near vision' and 'distant vision', respectively. Data regarding eye care, regularly recorded in the client files by more than $50 \%$ of the NHPs, are medical data involving 'use of eye medication', 'eye disease', and 'eye surgery in the past'. Less commonly recorded is 'the use of reading glasses' as well as 'eye pain'.

Inside of the $\mathrm{NH}$, (head) nurses and ward nurses $\left(\mathrm{chi}^{2}=309, \mathrm{df}=5, \mathrm{p}=0.000\right)$, and outside of the $\mathrm{NH}$, ophthalmologists and low vision specialists are most frequently contacted about eye related issues $\left(\mathrm{chi}^{2}=224\right.$, $\mathrm{df}=4, \mathrm{p}=0.000$ ). Opticians are rarely contacted, and optometrists and orthoptists are 'never' contacted by more than $50 \%$ of the NHPs. Moreover, $50 \%$ of the NHPs noted that collaboration with external eye care professionals is 'not structural'.

This study shows that, according to NHPs, relevant visual aspects are not structurally examined and recorded in the client files. Outside of the NH, NHPs tend to have a less frequent collaborative relationship with optometrists, orthoptists and opticians compared to ophthalmologists and low vision specialists. The NHP's role in providing eye care can be improved by development of guidelines for structural eye screening, improvement of recording in client files, and exploring plus undertaking collaboration with other eye care professionals.
\end{abstract}

Keywords: Long-term care, Visual functioning, Quality of eye care 


\section{Background}

\subsection{Nursing Home Residents in the Netherlands}

Currently, 4\% (112.000) of older Dutch adults [mean age, 85 years (de Klerk, 2011)] reside in long-term care facilities (www.rivm.nl). Nursing home residents tend to have multimorbidity that is associated with considerable disabilities and a high level of care dependency (Marengoni et al., 2011; Akner, 2009). In addition, eye diseases are highly prevalent in this target group. In the Dutch adult population the highest estimated prevalence $(>40 \%)$ of visual impairment (low vision and blindness) was found in the subgroup of residents in nursing homes (Limburg \& Keunen, 2009). Deterioration of visual function can be caused by eye diseases, such as cataract, glaucoma, diabetic retinopathy and macular degeneration (Bourne et al., 2013; Silverstone et al., 2000).

\subsection{Nursing Home Care in the Netherlands}

In Dutch nursing homes, care is delivered by multidisciplinary teams consisting of a nursing home physician (NHP), nurses, nurse assistants, and several therapists, including physiotherapists, occupational therapists, speech therapists, dieticians, psychologists etc. Nursing home medicine is a specifically acknowledged medical discipline [www.verenso.nl] (Schols et al., 2004). In Dutch nursing homes, NHPs work in different types of wards, including psychogeriatric, somatic and rehabilitation wards. The NHP is based at the nursing home, and is responsible for developing and evaluating the integrated care plan. This is formulated for every resident after admission and after performing an integral assessment of his or her problems (Schols \& Veer, 2005). Secondly, the NHP supervises the care team in the execution of multidisciplinary care (Hoek et al., 2003).

Eye care is also part of the integral nursing home care, and it impacts the health, comfort and wellbeing of residents (Brabyn et al., 2001). In the case of visual problems, the NHP can also contact specialists working outside of the nursing home, including ophthalmologists, optometrists, orthoptists, opticians or low vision specialists. In the Dutch system this may require an out of facility visit.

\subsection{Eye Diseases and Visual Functioning}

Residents with eye diseases fail in basic visual abilities and visual functioning, such as visual acuity, contrast sensitivity, and dark adaptation, as well as visual field loss (Owsley et al., 2007; Silverstone et al., 2000). Earlier studies have shown that eye problems are often insufficiently recorded in client files (Sinoo et al., 2014; Owsley et al., 2007) and that light conditions in many nursing homes are of poor quality (Aarts et al., 2014; Hegde \& Rhodes, 2010; Aarts \& Westerlaken, 2005) and often below the recommended threshold for visual function in older adults (750 -1000 lux) (Hegde \& Rhodes, 2010; Aarts \& Westerlaken, 2005; Sinoo et al., 2011).

Therefore, this study aimed to examine both the role of NHPs in eye care and in this respect also the relationship between NHPs and other involved professionals, by using a survey from the NHPs perspective.

The following research questions were addressed:

1) How do NHPs currently practice eye care for nursing home residents? 
2) Who are the NHPs' eye care collaboration partners inside and outside of the nursing home and how often do they cooperate?

\subsection{Theoretical Framework}

The study is using the World Health Organization's (WHO, 2002) ICF model (International Classification of Functioning, Disability, and Health), because it provides a multi-perspective approach to classify function and disabilities. Moreover the ICF can be considered to be a model for understanding the relationships between the resident, nursing home environment, and outcome factors, such as resident activity and participation.

The ICF framework relates health conditions (disorders or diseases), body functions and structures, and environmental factors (building related aspects and social aspects), to activities and participation of residents. The interaction of these components for residents with eye disease is shown in Figure 1.

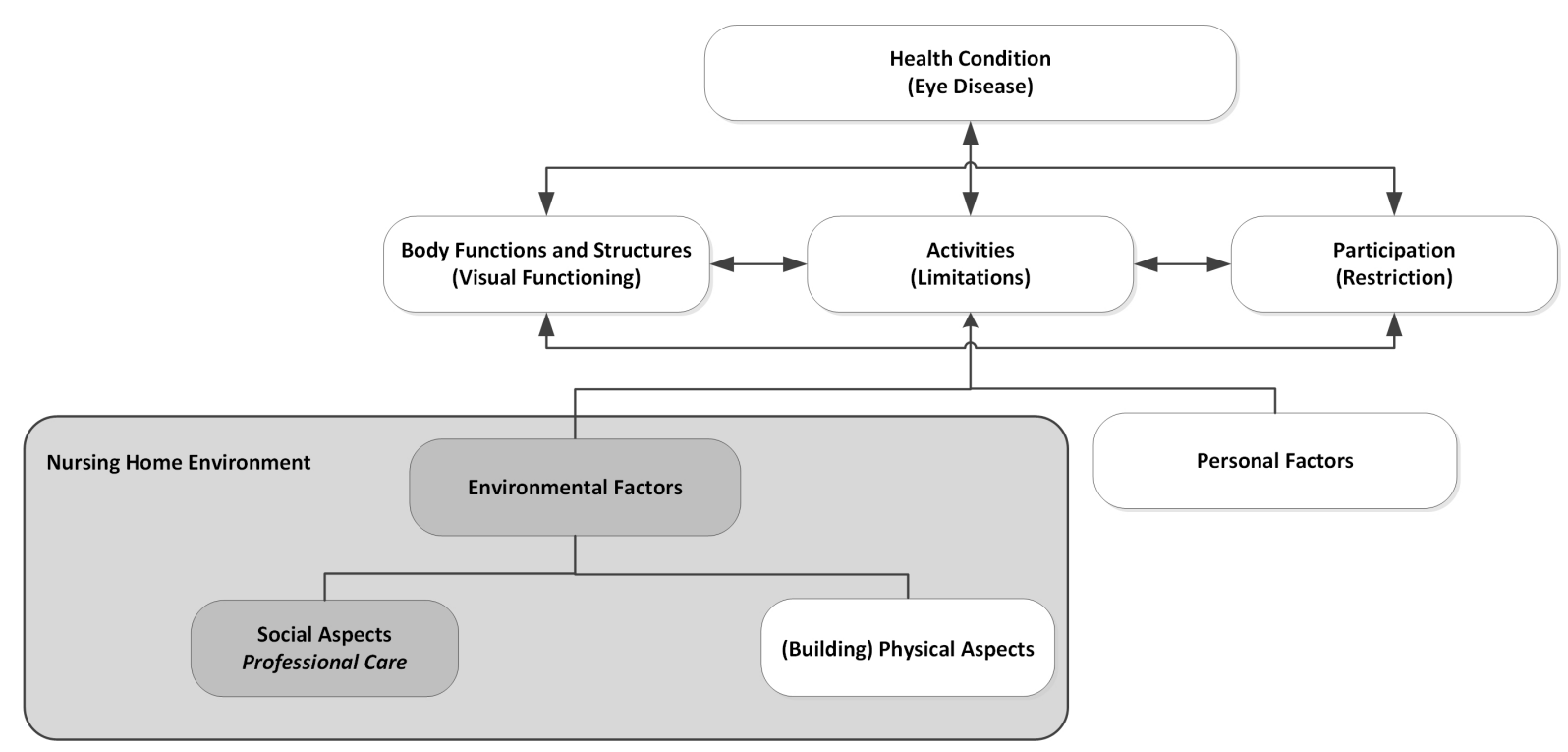

Figure 1. Professional care as a social aspect of the environmental factors, based on the ICF framework for disabilities and health (WHO, 2002)

Eye diseases as macular degeneration, glaucoma, cataracts or diabetic retinopathy (Bourne et al., 2013; Limburg \& Keunen, 2009) can be considered as "health condition" in the ICF model. These eye diseases may result in decreased visual functioning, due to decreased visual acuity, blurred vision, central vision loss or a reduction of the visual field (Owsley et al., 2007). Following ICF, this can be gathered under "body functions and structures". Both Body functions and health condition influence residents' daily activities and participation. (e.g. reading ability, social contacts). In ICF terms referred to as "activities" and "participation".

The environmental factors (Figure 1) represent among others social aspects (such as attitudes of professional caregivers, institutions, and laws), as well as building physical aspects (such as air quality, acoustics and light conditions). In the ICF framework building or indoor environmental aspects can be seen as non-pharmacological interventions to support people's 
self-management or health conditions (Kort, 2015).

With respect to light conditions, the nursing home environment can be facilitative or a barrier in the sense of visual functioning or visual comfort (Sinoo et al., 2011). The nursing home environment can even be a barrier in case of safety issues e.g. falls (Legood et al., 2002).

This study primarily focused on the social aspects of the nursing home environment. Among other things, social aspects involve all internal and external care professionals who collaborate in delivering eye care. This includes the recognition of visual problems, taking care of the treatment of visual problems and eye diseases and creating the best fitting environment for residents with visual problems. For the responsible care team, it is important to gain insight into both the visual problems of residents (Evans \& Rowlands, 2004; Owen et al., 2003) and the context in which the residents are living (Boyce, 2003).

\section{Methods}

A digital online survey was conducted using Survey Monkey software (www.surveymonkey.com).

The research team developed the questionnaire which was set up in three parts, as shown in table 1.In the first part, demographic data of the responding NHPs, such as gender and employment characteristics, were gathered.

Secondly, the screening and recording of visual problems were interrogated by forced choice questions and questions using a five-point Likert scale with the following choices: $1=$ never, $2=$ almost never, $3=$ sometimes, $4=$ frequently, and $5=$ always.

In the third part the questions about the inter professional collaboration between NHPs and eye care professionals were asked by using a nominal scale with six choices: score one represented no structural collaboration and the other five choices represented structural collaboration with the ophthalmologist, optometrist, orthoptist, optician, or low vision specialist.

Prior to dissemination of the survey, a pilot of the questionnaire was tested for content (comprehensibility and feasibility) by four experienced NHPs, who participated on a voluntary basis. Based on their responses (sent by email) some minor revisions were suggested, and questions were adapted accordingly. These NHPs were allowed to participate in the survey. 
Table 1. Outline of the set of questions

Part Topic Question

$1 \quad$ General demographics

Year of birth?

Gender?

What is the year of your certification/registration as an NHP?

In what type of ward are you employed?

2a Screening of visual functioning by the NHP*

$2 b \quad$ Recording in the client's file

3a Inter professional collaboration in eye care inside and outside of the nursing home

3b Formal collaboration outside the nursing home
How often do you examine aspects of visual functioning of the residents? (see Figure 3) **

Indicate how often you record the listed data in the client's (medical) file. (see Figure 2) **

How often do you contact the listed professionals or organizations if you suspect visual problems? (see Figure 4) **

Which eye care services are you formally consulting in your nursing home? $* * *$

*NHP = nursing home physician.

** Scale: never, almost never, sometimes, frequently, always.

*** Six choices: 1, no structural collaboration; 2 through 5, structural collaboration with an ophthalmologist, optometrist, orthoptist, optician, or low vision specialist.

\subsection{Recruitment of Participants and Data Analysis}

A link to the web-based survey was placed in the newsletter on the Verenso website www.verenso.nl. Verenso is the professional organization of nursing home physicians in the Netherlands. Over to 1500 members were able to read the newsletter. Thereby a potential sample of 1573 NHPs could be approached. The link was available from April 15, 2013 to August, 16 2013. Six weeks after the first publication on the Verenso website on April 15, a second reminder was provided on this website. No special incentives were used to increase the response rate.

Statistical analyses were performed using IBM Statistical Products and Service Solutions (SPSS) statistics 20 for Windows (IBM Corp., Armonk, NY: IBM Corp.) and Microsoft Excel 2010. For non-parametric statistics, the Friedman two-tailed test for k-related samples was employed to test differences in the frequencies of categories. The critical $p$-value was set at 0.05 .

\subsection{Ethical Considerations}

The survey submission was voluntary, and the data were received and processed anonymously. The only mentioned special point of interest was that the results would be published on the Verenso website for nursing home physicians. Verenso made no extra efforts 


\section{Macrothink}

Journal of Social Science Studies

ISSN 2329-9150 2016, Vol. 3, No. 1

to recruit participants. In the Netherlands, a survey considering collaboration is not needed to be reviewed following the Medical Research Involving Human Subjects Act (http://www.ccmo-online.nl).

\section{Results}

\subsection{Demographic Results}

In January 2014, the total group of NHPs involved 1573 physicians (males/females = 527/1046) (www.verenso.nl).

In total, 125 (response rate $<10 \%$ ) surveys were included in the analysis, seven of which were excluded. Only the data of the demographics were completed and all other data were missing. Table 2 shows the characteristics of the 118 nursing home physicians who fully completed the survey.

Table 2. Characteristics of the respondents $(n=118)$

\begin{tabular}{lll}
\hline Gender & $\boldsymbol{f}$ & $\mathbf{\%}$ \\
\hline Male & 37 & 31,4 \\
Female & 81 & 68,6 \\
Total & $\mathbf{1 1 8}$ & $\mathbf{1 0 0 , 0}$ \\
Certificated NHP & & \\
Receiving training & 10 & 8,5 \\
2010 or later & 19 & 16,1 \\
2000 - 2010 & 47 & 39,8 \\
Before 2000 & 42 & 35,6 \\
Total & $\mathbf{1 1 8}$ & $\mathbf{1 0 0 , 0}$ \\
Employment & & \\
Psycho Geriatric ward (PG) & 16 & 13,6 \\
Rehabilitation ward (R) & 10 & 8,5 \\
PG and somatic care & 46 & 39,0 \\
PG and R & 10 & 8,5 \\
PG, R and somatic care & 25 & 21,2 \\
Other & 11 & 9,2 \\
Total & $\mathbf{1 1 8}$ & $\mathbf{1 0 0 , 0}$ \\
\hline
\end{tabular}

Thirty-seven of the respondents (31.4\%) were male, and $81(69 \%)$ female. This proportion is representative of the population of NHPs, which consists of $33.5 \%$ male and $66.5 \%$ female NHPs.

Among the respondents, $10(8.5 \%)$ were in training to become a NHP and $19(16.1 \%)$ were 
recently certified (2010 or later). Most of the respondents (47 or 39.8\%) were certified from 2000 to 2010, and $42(35.6 \%)$ were certified before 2000. The majority of the NHPs were employed in a combination of wards: psychogeriatric and somatic wards (39\%), or psychogeriatric and rehabilitation wards $(8.5 \%)$, or psychogeriatric, somatic and rehabilitation wards $(21.2 \%)$.

\subsection{Activities of Nursing Home Physicians Regarding Eye Care for Dutch Nursing Home} Residents

Figure 2 shows the median scores for the diagnostic activities of nursing home physicians in terms of the residents' eye functions $(n=116)$.

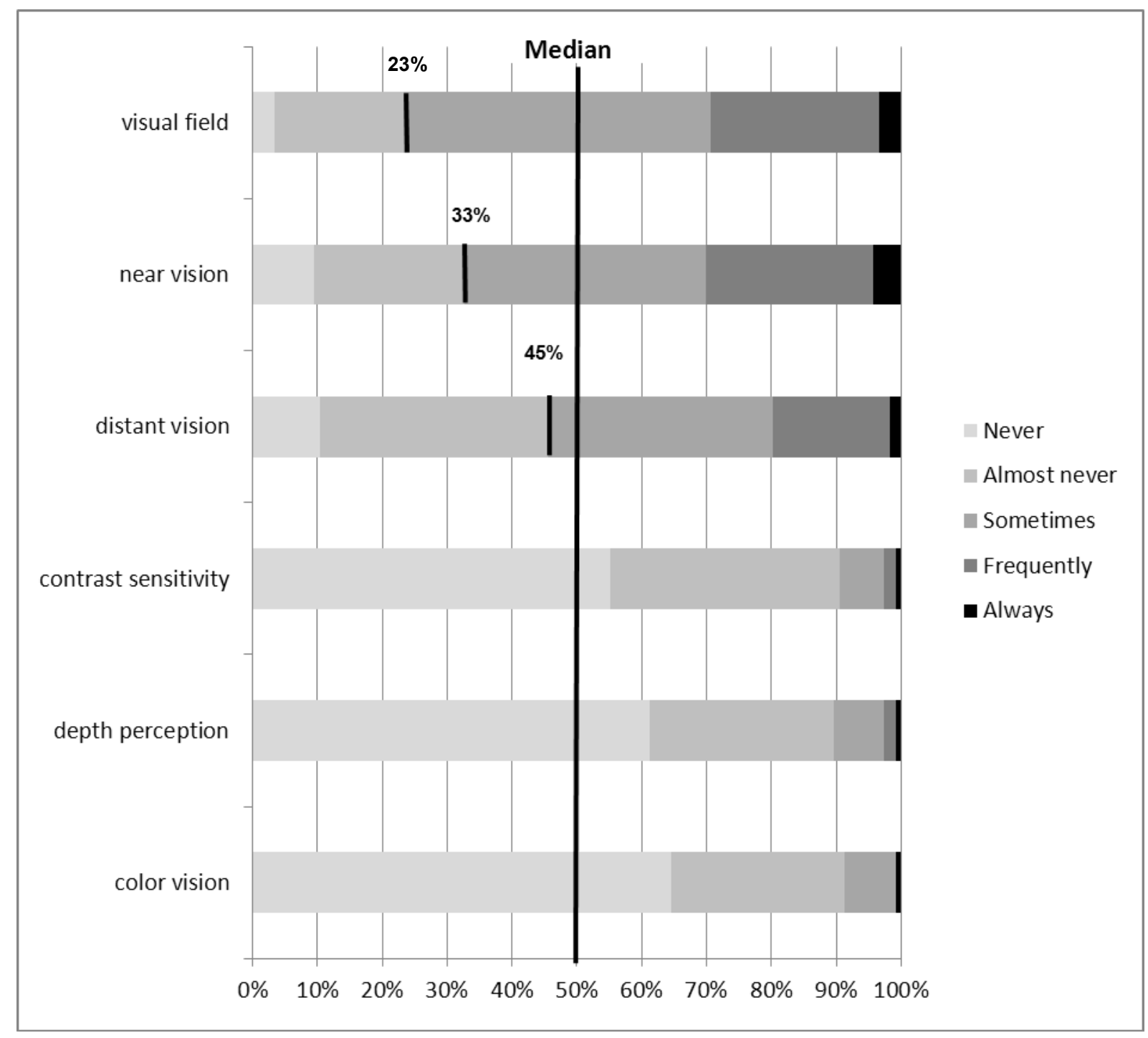

Figure 2. The visual aspects examined by the nursing home physicians $(\mathrm{n}=116,2$ missing)

Some of the respondents almost never or never examine 'visual field', 'near vision' and 'distant vision' $(23 \%, 33 \%$, or $45 \%$, respectively). Nevertheless these visuals aspects, are most frequently examined by the NHPs (Friedman: $\mathrm{chi}^{2}=383$, df $=5, \mathrm{p}=0.000$ ). 


\section{Macrothink}

Journal of Social Science Studies

ISSN 2329-9150

2016, Vol. 3, No. 1

The median line shows that more than $50 \%$ of the respondents never examine 'contrast sensitivity', 'depth perception', or 'color vision'. In Figure 3, the frequencies of eye-related issues (as recorded in the client files) are shown.

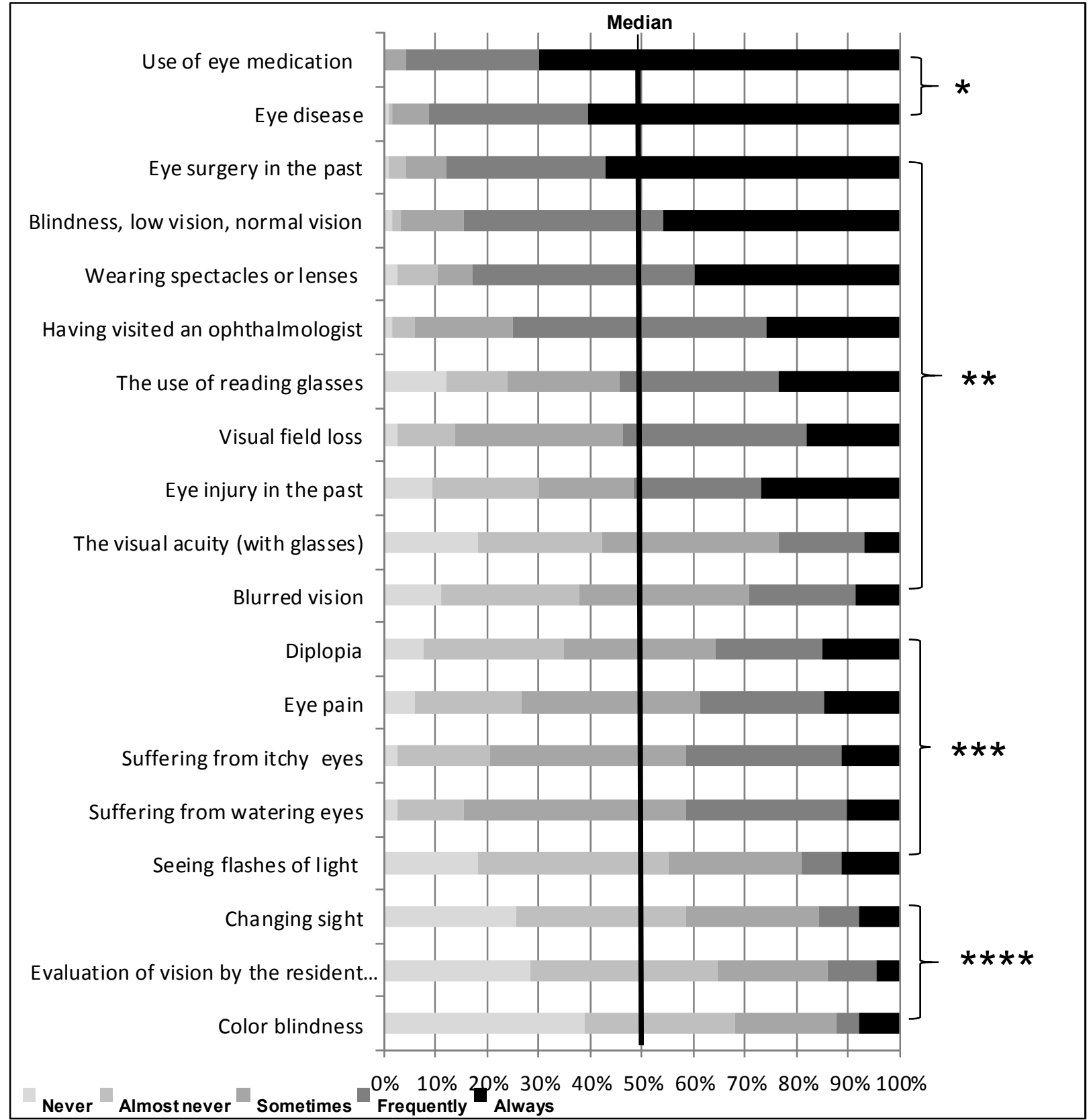

* Eye-related issues that are frequently or always recorded by at least $90 \%$ of the responding NHPs

** Eye-related issues that are frequently or always recorded by more than $50 \%$ of the responding NHPs

*** Eye related issues that are recorded sometimes or less often (almost never or never) by more than $50 \%$ of the NHPs

**** Eye related issues that are almost never or never recorded by more than $50 \%$ of the 


\section{Macrothink}

$\mathrm{NHPS}_{\mathrm{S}}$

Figure 3. The eye related issues that are recorded in the client files, according to the nursing home physicians ( $\mathrm{n}=116,2$ missing; 'having visited an ophthalmologist' $\mathrm{n}=115,3$ missing)

More than $90 \%$ of the nursing home physicians $\left(^{*}\right)$ frequently or always record 'eye disease' or the 'use of eye medication'. Nearly $90 \%$ do record whether their residents had undergone 'eye surgery in the past'. The eye related issues that are recorded frequently or always by more than $50 \%$ of the NHPs are marked by two asterisks $(* *)$.

With three asterisks $(* * *)$ data are marked that are recorded sometimes or less frequently by more than $50 \%$ of the NHPs. Data that are recorded almost never or less by more than $50 \%$ of the nursing home physicians are marked with four asterisks $(* * * *)$ These data involved: 'seeing flashes of light'; 'changing sight'; 'evaluation of vision by the resident himself, 'and 'color blindness'.

3.3 Collaboration with Professional Partners Regarding Eye Care, Inside and Outside of the Nursing Home

In Figure 4, which is based on the ICF model, the median score of the frequency of contacting another professional inside or outside of the nursing home is calculated (i.e., in cases in which the NHP suspects eye problems in the residents).

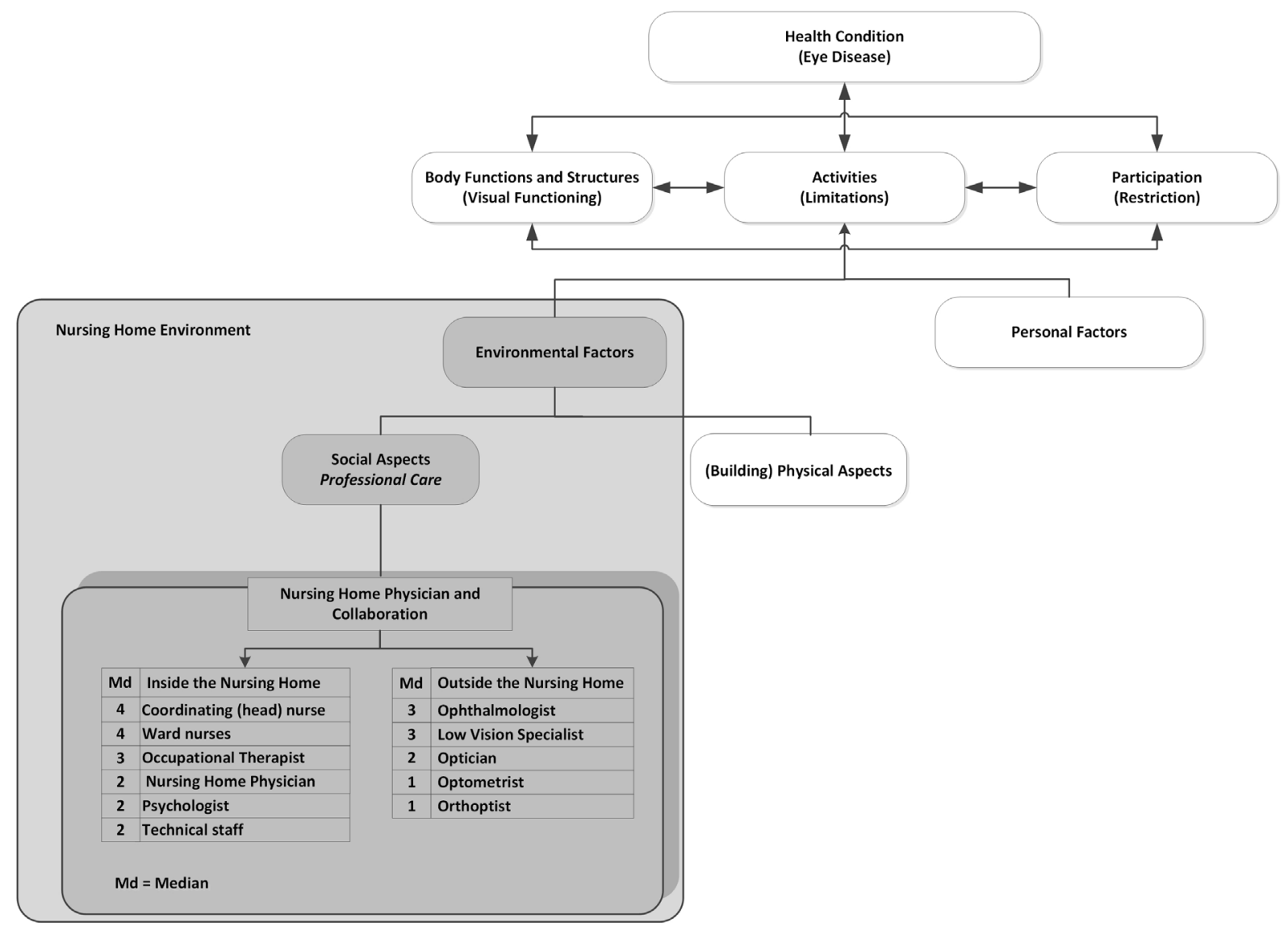


Figure 4. Median scores (Md) of contact with care professionals inside and outside of the nursing home, in case of suspected eye problems (illustrated as social aspects within the ICF framework): 1 = never, 2 = almost never, $3=$ sometimes, $4=$ frequently, $5=$ always

Figure 4 shows the median scores of the extent to which care professionals inside and outside of nursing homes are contacted.

A significant difference was observed in terms of the extent to which the six professional caregivers inside of the nursing home are contacted (Friedman: $\operatorname{chi}^{2}=309, \mathrm{df}=5, \mathrm{p}=0.000$ ).

More than $50 \%$ of the respondents 'almost never' $(\mathrm{Md}=2)$ contact a colleague nursing home physician, psychologist or technical staff member. The coordinating (head) nurse or the ward nurse is 'frequently' contacted by more than $50 \%$ of the respondents $(\mathrm{Md}=4)$. The occupational therapist is contacted 'sometimes' $(\mathrm{Md}=3)$.

The extent to which the five professional caregivers outside of the nursing home are contacted differed significantly (Friedman: $\mathrm{chi}^{2}=224, \mathrm{df}=4, \mathrm{p}=0.000$ ).

Ophthalmologists and the low vision specialists are contacted 'sometimes' $(\mathrm{Md}=3)$ by more than $50 \%$ of the NHPs. Opticians, optometrists and orthoptists are contacted (almost) never $(\mathrm{Md}=1$ or 2$)$.

The question whether the collaboration with eye care professionals, if present, can be considered to be structural by the NHPs was answered positively by nearly half of the respondents $(49.6 \%)$; the other half $(50.4 \%)$ did not consider this collaboration to be structural.

\section{Discussion}

Identifying visual problems is the first step in improving the quality of eye care in nursing homes. Older adults are advised to have a regular (once a year) eye screening even in the absence of established pathology (Evans \& Rowlands, 2004). In the Netherlands, the Dutch Ophthalmological Association recommends an eye examination for all nursing home residents upon admission (van Rens, 2014). This includes refraction, assessment of the anterior and posterior segments of the eyes, and intraocular pressure (IOP) measurements. This examination should be repeated every two or three years.

This study showed that not all NHPs conduct regular eye screenings. Therefore, it is still relevant for NHPs to be more aware of the importance of doing such eye screenings.

A first step in enhancing awareness of care professionals on visual problems might be the use of a feasible Visual Functioning Questionnaire (VFQ). The NEI-VFQ 25 questionnaire, for instance is originally developed by the National Eye Institute (NEI) in the USA, and provides a self-reported measure of visual functioning, which is associated with visual acuity, binocular status and differences in acuity between eyes (Owen et al., 2006). Family or professional caregivers can complete this questionnaire. The NEI-VFQ 25 tool does not provide a complete picture. An eye screening or even an eye examination is still necessary for diagnosis of visual problems. Nevertheless, the questionnaire gives an insight into the experienced visual functioning. This may be a first step in enhancing awareness of care professionals on visual problems. 
NHPs might also chose to collaborate in a more structural way with eye care professionals outside of the nursing home, such as ophthalmologists or optometrists. These professionals might be called in to further examination of the residents if (serious) visual impairment is suspected by the NHP or other nursing home professionals.

In this study, only half of the NHPs considered the collaboration with eye care professionals outside of the nursing home to be structural. In the professional profile of elderly care physicians (www.verenso.nl) their role is described as: 'objective-focused collaboration (i.e. network formation) is an absolute must'. Unfortunately, up until now adequate integral eye care for nursing home residents is not an established care pathway in the Netherlands. An established care pathway is a process of interprofessional collaboration and may be described by the four dimensions of D'Amour et al. (2008).

Interprofessional collaboration, thereby, is defined as "the process in which different professionals work together to positively impact healthcare", according to Zwarenstein et al. (2009).

D'Amour et al. (2008) have developed a typology of collaboration of healthcare professionals /organizations expressed by four dimensions:

1). shared goals and vision, referring to the existence of common goals;

2). internalization, referring to the awareness of interdependence of care professionals;

3 ). formalization, referring to the use of documented procedures; and

4). governance, referring to leadership that supports collaboration.

The first two dimensions describe the relationship between professional caregivers and their awareness of interdependency. Interprofessional collaboration emphasizes that professionals value the expertise and contributions of other healthcare professionals.

In nursing homes, the first two dimensions of shared goals, vision and the awareness of interdependency regarding eye care implicate that the NHP and other internal and external health care professionals share data about the visual status of the residents. The coordinating (head) nurse and the ward nurses need this information to retrofit the environment by taking into account the residents' visual capacities.

Therefore visual functioning must be recorded in the client file to achieve appropriate tailor made care. This step is not always commonly conducted in a complete and tailored way, as is shown in this study. The most frequently recorded data on visual functioning and visual impairments by the NHPs in this study involved medical aspects, such as 'eye disease' or 'use of eye medication and whether residents had undergone 'eye surgery in the past'. Data as visual field loss, changing sight and suffering from itchy eyes were less frequently recorded.

The third dimension in the D'Amour typology is formalization. In the Netherlands, however, establishment of a complete eye care model with external professionals such as ophthalmologists, optometrists, orthoptists and low vision specialists, is not yet formalized. This is an ongoing process. Currently, in some nursing homes in the Netherlands, NHPs are already able to consult an optometrist on demand.

In this study, the ICF framework was chosen as a theoretical framework. This framework relates environmental factors (building related aspects and social aspects) to activities and 
participation of residents. In earlier studies, the ICF framework was suitable to investigate light conditions, representing an environmental (building related) aspect of nursing homes (Sinoo et al., 2014; Hegde \& Rhodes, 2010).

In this study, the focus was on professional care and interprofessional collaboration, both representing environmental social aspects. We were able to investigate NHPs interprofessional collaboration related to eye care, with other professionals inside and outside of nursing homes. As described in figure 1, interprofessional collaboration in eye care impacts health care in ICF terms, meaning that it limits or facilitates residents in their daily activities or in participation.

The Dutch professional organization of NHPs (Verenso), states that disorders of the special senses (vision and hearing) are a relevant and urgent point of interest (www.verenso.nl). Nevertheless, this study shows that NHPs' activities associated with the provision of adequate eye care in the nursing home can and must be improved in terms of more and regular eye screenings, better recording of information in the client files, and by interprofessional collaboration.

\subsection{Study Limitations}

The most apparent limitation of this study is the low response rate $(<10 \%)$. To generalize the findings of a survey, a response rate of $30-80 \%$ would be reasonable; however, internet surveys typically have lower response rates than other types of surveys (Sitzia \& Wood, 1998). Nevertheless, the proportion of $31.4 \%$ male respondents, and $69 \%$ female respondents is representative for the total population of NHPs, which consists of $33.5 \%$ male and $66.5 \%$ female NHPs. In this study, some measures were adopted to increase the response rate, including the assurance of confidentiality and placing a reminder on the website.

In addition, the imperfect response rate, combined with the non-random sampling procedure may also have led to a selection effect in which, those who answered the survey may have had special interest in this topic. Overall this may lead to generalizability problems and therefore, one should be cautious in drawing overall conclusions.

Despite this, the results of this study fit with earlier field studies in Dutch nursing homes showing low awareness of care professionals on visual functioning (Sinoo et al., 2012; Sinoo et al., 2014).

\section{Conclusions}

This study shows that relevant visual aspects in nursing home residents are not structurally examined and recorded in client files and also that the inter professional collaboration in eye care can be improved. This requires a more proactive approach by NHPs themselves. In addition more attention must be paid to the development of an integral eye care model for nursing home residents including the relevant professionals of the internal multidisciplinary team and external specialized professionals, such as ophthalmologists, optometrists, orthoptists and low vision specialists.

\section{Practical Implications}

Awareness of nursing home residents' visual functioning and insight into the consequences for daily functioning is highly relevant for adapting basic daily care from NHPs in alignment to the resident's needs. 


\section{Macrothink}

\section{Acknowledgements}

The professional organization of nursing home physicians in the Netherlands (Verenso) is thanked for its cooperation in publishing the survey monkey link on their website. All participating nursing home physicians are thanked for their support and cooperation in completing the survey. Assistant Professor Cas Kruitwagen (MSc) at the Julius Centre UMC Utrecht is thanked for his advice in the statistical analysis.

\section{Authors' contributions}

Research team: MS, JS; data collection: MS; data analysis: MS, JS, and HK; manuscript preparation: MS, JS, HK, and MvT

\section{List of abbreviations}

ICF: International Classification of Functioning

NHPs: Nursing Home Physicians

NH(s): Nursing Home(s)

\section{References}

Aarts, M. P. J., Aries, M. B. C., Straathof, J., \& Hoof, J. van. (2014). Dynamic lighting systems in psychogeriatric care facilities in the Netherlands: a quantitative and qualitative analysis of stakeholders' responses and applied technology. Indoor and Built Environment, O(0), 1-14. http://ibe.sagepub.com/content/early/2014/05/07/1420326X14532387

Aarts, M. P. J., \& Westerlaken, A. C. (2005). Field study of visual and biological light conditions of independently living elderly people. Gerontechnology, 4, 141-152. http://dx.doi.org/10.4017/gt.2005.04.03.004.00

Akner, G. (2009). Analysis of multimorbidity in individual elderly nursing home residents. Development of a multimorbidity matrix. Archives of Gerontology and Geriatrics, 49, 413-419. http://dx.doi.org/10.1016/j.archger.2008.12.009

Bourne, R. A. et al. (2013). Causes of vision loss worldwide, 1990-2010: a systematic analysis. The Lancet Global Health, 1(6), 339-349. http://dx.doi.org/10.1016/S2214-109X(13)70113-X

Boyce, P. R. (2003). Lighting for the elderly. Technology and Disability, 15(3), 165-180. Brabyn, J., Schneck, M., \& Haegerstrom-Portnoy G. (2001). The Smith/Kettlewell Institute (SKI) Longitudinal study of vision function and its impact among the elderly: an overview. $\begin{array}{llll}\text { Optometry and } \quad \text { Vision } & \text { 264-269. }\end{array}$ http://dx.doi.org/10.1201/9780203426340.ch12

D’Amour, D., Goulet, L., Labadie, J. F., San Martïn-Rodriguez, L., \& Pineault, R. (2008). A model and typology of collaboration between professional in healthcare organizations. $B M C$ Health Services Research, 8, 188. http://dx.doi.org/10.1186/1472-6963-8-188

Evans, B. J. W., \& Rowlands, G. (2004). Review Article: Correctable visual impairment in older people: a major unmet need. Opthalmic and Physiological Optics, 24, 61-180. http://dx.doi.org/10.1111/j.1475-1313.2004.00197.x

Hegde, A. L., \& Rhodes, R. (2010). Assessment of lighting in independent living facilities and residents' perceptions. Journal of Applied Gerontology, 29(3), 381-390. http://dx.doi.org/10.1177/0733464809343105 
Hoek, J. F., Ribbe, M. W., Hertogh, C. M. P. M., Vleuten, C. P. M., van der. (2003). The Role of the specialist physician in nursing homes: the Netherlands experience. International Journal of Geriatric Psychiatry, 18, 244-249. http://dx.doi.org/10.1002/gps.816

Klerk, M. de. (2011). Zorg in de laatste jaren, The Hague, SCP [In Dutch].

Kort, H. S. M. (2015) Building for Health; Beyond Satisfaction. Proceedings Healthy Buildings Europe 2015, paper id 614.

Legood R., Scuffham P. \& Cryer C. (2002). Are we blind to injuries in the visually impaired? A review of the literature. Injury Prevention, 8, 155-160. http://dx.doi.org/10.1136/ip.8.2.155

Limburg, H. J. E. E., \& Keunen, J. E. E., van. (2009). Blindness and low vision in The Netherlands from 2000 to 2020- modeling as a tool for focused intervention. Ophthalmic Epidemiology, 16 (6), 362-369. http://dx.doi.org/10.3109/09286580903312251

Marengoni, A. et al. (2011). Aging with multimorbidity: a systematic review of the literature. Ageing Research Reviews, 10, 430-439. http://dx.doi.org/10.1016/j.arr.2011.03.003

Owen, C. G. et al. (2006) Is the NEI-VFQ-25 a useful tool in identifying visual impairment in an elderly population? BMC Ophthalmology, 6, 24. http://dx.doi.org/10.1186/1471-2415-6-24 Owsley, C. et al. (2007). The visual status of older persons residing in nursing homes. Arch Ophthalmol, 125(7), 925-930. http://dx.doi.org/10.1001/archopht.125.7.925

Rens, G. H. M. B. van, Vreeken, H. L., \& van Nispen, R. M. A. (2014). Nederlands Oogheelkundig Gezelschap Richtlijn Visusstoornissen, revalidatie en verwijzing 2014. [In Dutch]

Schols, J. M. G. A., Crebolder, H. F. J. M., \& van Weel, C. (2004). Nursing home and nursing home physician: the Dutch experience. Journal of the American Medical Directors Association, 5, 207-212.http://dx.doi.org/10.1016/S1525-8610(04)70116-4

Schols, J. M. G. A., \& Veer, A. J. E. (2005). Information exchange between general practioner and nursing home physician in the Netherlands. Journal of the American Medical Directors Association, 6(3), 219-225. http://dx.doi.org/10.1016/j.jamda.2005.03.006

Silverstone, B., Lang, M. A., Rosenthal, B. P., \& Faye, E. E. (eds.) (2000). The lighthouse handbook on vision impairment and vision rehabilitation, Volumes I and II, Oxford UK, Oxford University Press.

Sinoo, M. M., van Tilborg, M., Schols, J. M. G. A., \& Kort, H. S. M. (2014). Age Related Visual Pathologies among Nursing Home Residents: An Evaluation of Light Conditions and Recording in Client Files. World Journal of Social Science Research, 1(2), 27-42.

Sinoo, M. M., van Hoof, J., Kort, H. S. M. (2011). Light conditions in the nursing home. Building \& Environment, 46, 1917-1927. http://dx.doi.org/10.1016/j.buildenv.2011.03.013

Sinoo, M. M., Kort, H. S. M., \& Duijnstee, M. S. H. (2012). Visual functioning in nursing home residents: information in client records. Journal of Clinical Nursing, 21, 1913-1921. http://dx.doi.org/10.1111/j.1365-2702.2012.04128.x

Sitzia, J., \& Wood, N. (1998). Response rate in patient satisfaction research: an analysis of 210 published studies. International Journal for Quality in health Care, 10(4), 311-317. http://dx.doi.org/10.1093/intqhe/10.4.311

WHO, World Health Organisation. Towards a Common Language for Functioning, Disability 


\section{Macrothink}

Journal of Social Science Studies

ISSN 2329-9150 2016, Vol. 3, No. 1

and Health, World Health Organization, Geneva; 2002. ICF, International Classification of Functioning Disability and Health 2002. Geneva. Retrieved September 25, 2015, from http://www.who.int/classifications/icf/training/icfbeginnersguide.pdf

Zwarenstein, M., Coldman, J., \& Reeves, S. (2009). Interprofessional collaboration: effects of practice-based interventions on professional practice and healthcare outcomes, The Cochrane Library, 3. http://dx.doi.org/10.1002/14651858.cd000072.pub2

\section{Websites}

CCMO Centrale commissie Mensgebonden Onderzoek: http://www.ccmo-online.nl

Accessed September 26, 2015.

Survey Monkey, free online questionnaire and survey software. www.surveymonkey.nl. Accessed September 26, 2015.

Verenso, the Dutch Association of Elderly Care Physicians and Social Geriatricians. www.verenso.nl. Accessed September 26, 2015.

Verenso professional profile elderly care physician http://www.verenso.nl/assets/Uploads/Downloads/Richtlijnen/VER0026-Professionalprofilebroch-DEF.pdf. Accessed November 25, 2015.

\section{Copyright Disclaimer}

Copyright reserved by the author(s).

This article is an open-access article distributed under the terms and conditions of the Creative Commons Attribution license (http://creativecommons.org/licenses/by/3.0/). 